\title{
INFLUÊNCIA DO CROMO E NIÓBIO NO DESEMPENHO QUANTO AO DESGASTE ABRASIVO EM REVESTIMENTOS DUROS*
}

Bráulio Campagnaro Santana ${ }^{1}$

\section{Resumo}

$\mathrm{Na}$ indústria da mineração, a liga $\mathrm{Fe}-\mathrm{Cr}-\mathrm{C}$ destaca-se como um revestimento duro em chapas de desgaste objetivando aumentar a vida útil do ativo. Três ligas, duas delas contendo Fe-Cr-C, sendo uma com aproximadamente $28 \%$ (p) de $\mathrm{Cr}$ e outra com 38\% (p) de Cr e uma terceira liga com 24\% (p) de $\mathrm{Cr}$ e 7,0\% (p) de Nb foram levadas a ensaios de desgaste abrasivo roda de borracha conforme norma ASTM G65-04, além de medições de dureza, microdureza e caracterizações microestruturais. Constatou-se que os revestimentos contendo $\mathrm{Nb}$, depositados com uma ou duas camadas de solda, possuem maior resistência ao desgaste abrasivo, seguidos pelos com maior teor de $\mathrm{Cr}$. Os revestimentos que possuem maior fração volumétrica de carbonetos, finamente distribuídos na matriz, apresentaram os melhores resultados na resistência ao desgaste. Analisando no microscópio confocal $3 \mathrm{D}$ os revestimentos contendo $\mathrm{Cr}$, notou-se que os mecanismos de desgaste são do tipo microcorte e microssulcamento, enquanto naqueles contendo nióbio prevalece 0 desgaste por rolamento em boa parte da superfície. A liga contendo $\mathrm{Nb}$ apresenta $\mathrm{o}$ melhor desempenho na resistência ao desgaste abrasivo em relação às demais, e se torna viável economicamente sua aplicação na indústria.

Palavras-chave: Revestimentos duros; Transferência de minério e pelotas; Mecanismos de desgaste.

\section{INFLUENCE OF CHROMIUM AND NIOBIUM IN PERFORMANCE ON ABRASIVE WEAR IN HARD COATINGS}

\section{Abstract}

In the mining industry, the Fe-Cr-C alloy stands out as a hard coating on wear plates in order to increase the useful life of the active. Three alloys, two of them containing Fe-Cr-C, one with approximately $28 \%$ (p) $\mathrm{Cr}$ and another with $38 \%$ (p) $\mathrm{Cr}$ and one third alloy was specified with $24 \%(\mathrm{w})$ of $\mathrm{Cr}$ and $7.0 \%(\mathrm{w})$ of $\mathrm{Nb}$ were subjected to abrasive wear tests rubber wheel according to standard ASTM G65-04, in addition to hardness measurements, microhardness and microstructural characterization by. It was found that $\mathrm{Nb}$ coatings deposited with one or two layers of solder have higher resistance to abrasive wear, followed by coatings with higher $\mathrm{Cr}$. The coatings that have the largest volumetric fraction of carbides, finely distributed in the matrix, presented the best results in the resistance to wear. Analyzing the Cr containing coatings on the 3D confocal microscope, it was observed that the mechanisms of wear are of the microccuting and microploughing, while in those containing niobium, the rolling wear prevails in a good part of the surface. The alloy containing $\mathrm{Nb}$ presents the best performance in the resistance to abrasive wear in relation to the others and it becomes economically viable its application in the industry.

Keywords: Hard coatings; Transfer of ore and pellets; Mechanisms of wear.

Bacharel em Engenharia Mecânica, mestrando, programa de pós-graduação em engenharia metalúrgica e de materiais, Instituto Federal do Espírito Santo, Vitória, Espírito Santo, Brasil.. 


\section{INTRODUÇÃO}

Na logística da commoditie minério de ferro nas indústrias de mineração, o fator desgaste se torna um dos principais modos de falha em equipamentos e componentes. Em 1976, Eyre atribuiu que dentre os tipos de desgaste mais comuns encontrados na área industrial, $50 \%$ correspondem ao desgaste abrasivo.

As falhas caracterizadas por desgaste ocasionam paralisações emergenciais das máquinas. Além disso, o custo por manutenção preventiva também se torna alto em indústrias de mineração, pois o volume de material transportado é muito elevado. Em uma grande indústria de mineração, os custos diretos anuais médios podem chegar a $\mathrm{R} \$ 4.000 .000,00$ para um volume médio de minério transportado aproximadamente de 100.000.000,00 t.

Diversas ligas atualmente são aplicadas como revestimento duro com o objetivo de proteger materiais de sacrifício em equipamentos. Em chutes de transferência de minério, uma das ligas mais comuns utilizadas é a Fe-C-Cr.

Uma das formas de tornar o produto mais barato (chapa + revestimento) está relacionada à técnica de deposição do revestimento através de processos de soldagem.

Utilizando-se a técnica de soldagem weld overlay por arame tubular e a norma ASTM G 65-04 (ensaios de resistência ao desgaste abrasivo através do abrasômetro roda de borracha), este trabalho terá a proposta de selecionar entre algumas ligas, a de melhor desempenho quanto ao desgaste abrasivo e viabilizar economicamente sua aplicação em campo.

\subsection{Objetivo Geral}

Estudar a influência da adição de $\mathrm{Nb}$, bem como do aumento do teor de $\mathrm{Cr}$, sobre a resistência ao desgaste abrasivo de ligas $\mathrm{Fe}-\mathrm{C}-\mathrm{Cr}$ aplicadas como revestimento de chapas de transferência de pelotas de minério de ferro.

\subsection{Objetivos Específicos}

- Calcular o volume de desgaste dos três tipos de revestimentos utilizando ensaio de desgaste por roda de borracha conforme norma ASTM G65-04;

- Caracterizar e correlacionar as microestruturas dos revestimentos com os volumes de desgaste calculados;

- Correlacionar o volume desgastado das diferentes ligas com suas respectivas durezas;

- Comparar o desempenho na resistência ao desgaste abrasivo dos materiais quando soldados tanto em duas quanto em apenas uma camada de deposição;

- Realizar um estudo comparativo através de gráficos da resistência ao desgaste abrasivo das ligas de revestimento e propor a aplicação em campo nos equipamentos de transferência de minério de ferro e pelotas utilizados na indústria de mineração;

- Estudar a influência do elemento nióbio e da fração volumétrica de carbonetos distribuídos na matriz no desempenho quanto ao desgaste abrasivo;

- Utilizar a microscopia confocal 3D para realizar as análises dos mecanismos de desgaste das ligas de revestimentos duros. Realizar a análise de viabilidade econômica comparando os desempenhos dos revestimentos na resistência ao desgaste abrasivo e os respectivos custos de mercado; 


\subsection{Revisão Bibliográfica}

Dias e Gomes (2003) [1] afirmam que o fenômeno do desgaste é de maneira geral, o deslocamento de material causado pela presença de partículas duras que estão entre ou embutidas em uma ou ambas as superfícies em movimento relativo.

Bhushan et. al (1991) [2] define que o desgaste se dá pelo processo de remoção de material de uma superfície (corpo) devido ao rolamento ou deslizamento de partículas (contra corpo) ou em razão de reações que ocorrem na superfície do material.

Zum Gahr (1992) [3] define desgaste abrasivo como sendo o deslocamento de material causado pela presença de partículas duras entre superfícies, embutidas em uma ou ambas superfícies em movimento relativo, ou ainda por presença de protuberâncias duras em uma ou ambas superfícies em movimento relativo.

Em relação ao tipo de abrasão, há vários mecanismos de desgaste descritos na literatura, entre eles, abrasão por goivagem, abrasão a alta tensão (moagem) e abrasão a baixa tensão (riscamento), sendo este último, objeto desse estudo. A abrasão a baixa tensão resulta do deslizamento de partículas livres sobre a superfície do componente. Na Figura 1, tem-se um exemplo da abrasão em chutes de minério de ferro e pelotas localizados na indústria de mineração.

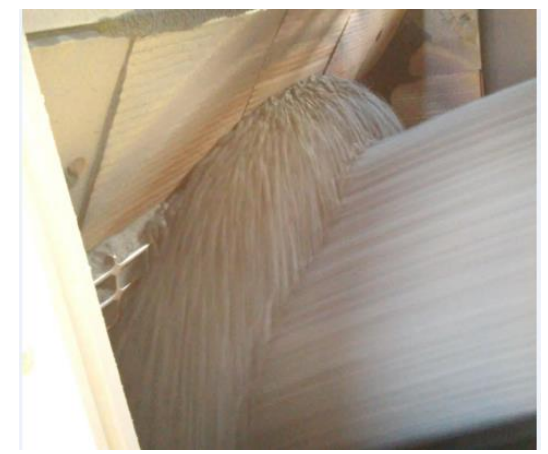

Figura 1. Pelotas de minério atingindo as chapas de desgaste em chutes de transferência.

\subsubsection{Microestrutura, dureza e resistência ao desgaste}

Segundo Brandi el al. (1992) [4], o teor de carbono aumenta a resistência ao desgaste dos aços perlíticos com o aumento do endurecimento. Os carbonetos aumentam a resistência ao desgaste com o aumento na quantidade, distribuição uniforme e forma mais adequada, por outro lado, não suportam elevados impactos.

A fração volumétrica dos carbonetos é um dos mais importantes parâmetros microestruturais que afetam a resistência ao desgaste abrasivo. Hutchings (1992) afirma que para uma determinada fração volumétrica de carbonetos, a resistência ao desgaste abrasivo é aumentada para carbonetos finamente distribuídos com um pequeno espaço entre partículas. De acordo com a análise antes citada, na Figura 4 nota-se o efeito do tamanho e fração volumétrica dos carbonetos distribuídos.

\section{MATERIAIS E MÉTODOS}

\subsection{Seleção das ligas de revestimento e metal de base}

Para a confecção dos corpos de prova, primeiramente foram definidas as ligas de revestimento a serem estudadas. São encontradas facilmente na indústria de 
consumíveis de solda (arames) e seus preços comerciais aproximados se encontram na Tabela 1.

Tabela 1. Custo comercial aproximado das ligas escolhidas.

\begin{tabular}{|c|c|}
\hline Liga & Custo $(\mathrm{R} \$ / \mathrm{Kg})$ \\
\hline T63 - FeCrC (referência) & 40,00 \\
\hline T65 - FeCrCNb & 50,00 \\
\hline T70 - FeCrC & 70,00 \\
\hline
\end{tabular}

Nas Tabelas 2, são visualizadas as composições químicas bem como os respectivos parâmetros de soldagem definidos. Estes foram definidos de acordo com as características técnicas das ligas.

Tabela 2. Ligas utilizadas como revestimento duro para proteção ao desgaste.

\begin{tabular}{rccccccc}
\hline Liga & $\mathbf{C ~ ( \% )}$ & $\mathbf{C r}(\%)$ & $\mathbf{N b}(\%)$ & $\mathbf{B ~ ( \% )}$ & $\mathrm{Si} \mathrm{( \% )}$ & Fe (\%) & $\begin{array}{c}\text { Dureza } \\
\text { (HRC) }\end{array}$ \\
\hline T63 & 5 & 28,5 & - & - & - & - & $58-62$ \\
\hline T65 & 5,5 & 24 & 7 & 2 & - & - & $60-65$ \\
\hline T70 & $5,0-6,0$ & $38,0-42,0$ & - & $1,5-2,0$ & $0,8-1,0$ & - & $66-68$ \\
\hline
\end{tabular}

Dentre as ligas escolhidas, a T63 atualmente é a aplicada em campo para revestimentos duros em chapas de desgaste instaladas nos chutes de transferência de uma grande mineradora. Dessa forma, ela foi utilizada como sendo uma composição referência em relação às demais. O metal de base de todas as ligas é composto por aço ASTM A-36. Uma das vantagens deste aço é a soldabilidade, portanto são os mais comumente utilizados como material de base nas fabricações de chapas ou placas com revestimento duro encontradas nos chutes de transferência de minério de ferro tornando o produto mais atrativo e competitivo em relação aos custos.

\subsection{Definição do processo e parâmetros de soldagem}

O processo de soldagem definido para a confecção dos corpos de prova foi o arame tubular. As ligas foram soldadas conforme os parâmetros definidos de forma padronizada mostrados na Tabela 3. Não será avaliada neste trabalho a influência dos parâmetros de soldagem na formação das microestruturas dos revestimentos, e sim, somente uma análise comparativa da resistência ao desgaste abrasivo.

Tabela 3. Parâmetros de soldagem para confecção dos corpos de prova.

\begin{tabular}{cccccc}
\hline $\begin{array}{c}\text { Processo } \\
\text { Arame Tubular }\end{array}$ & $\begin{array}{c}\text { Corrente } \\
\text { (A) }\end{array}$ & $\begin{array}{c}\text { Tensão } \\
\text { (V) }\end{array}$ & $\begin{array}{c}\text { Velocidade } \\
\text { soldagem } \\
(\mathbf{m m} / \mathbf{s})\end{array}$ & $\begin{array}{c}\text { Velocidade do } \\
\text { arame } \\
\text { (cm/s) }\end{array}$ & $\begin{array}{c}\text { Diâmetro do } \\
\text { arame }(\mathbf{m m})\end{array}$ \\
\hline T63, T65 e T70 & 450 & 35 & 7,3 & 1,3 & 2,4 \\
\hline
\end{tabular}

\subsection{Preparação dos corpos de prova}

Para o início do processo de soldagem das ligas, foram preparadas 03 chapas bases em A-36, em um padrão de $250 \mathrm{~mm} \times 150 \mathrm{~mm} \times 25,4 \mathrm{~mm}$. As chapas foram esmerilhadas e preaquecidas aproximadamente em $150^{\circ} \mathrm{C}$.

Após o procedimento de soldagem, as chapas foram usinadas em um plasma a fim de se obter as dimensões próximas à norma ASTM G65-04, ou seja, 3" x 1" x 0,5" (dimensões recomendadas para o ensaio de desgaste abrasivo roda de borracha). 
Após o plasma, as amostras foram usinadas por processos de eletro-erosão e retífica ficando nas dimensões adequadas para o ensaio de desgaste abrasivo roda de borracha. Na Figura 2, tem-se as 15 amostras das diferentes ligas depositadas para os mesmos parâmetros de soldagem estabelecidos.

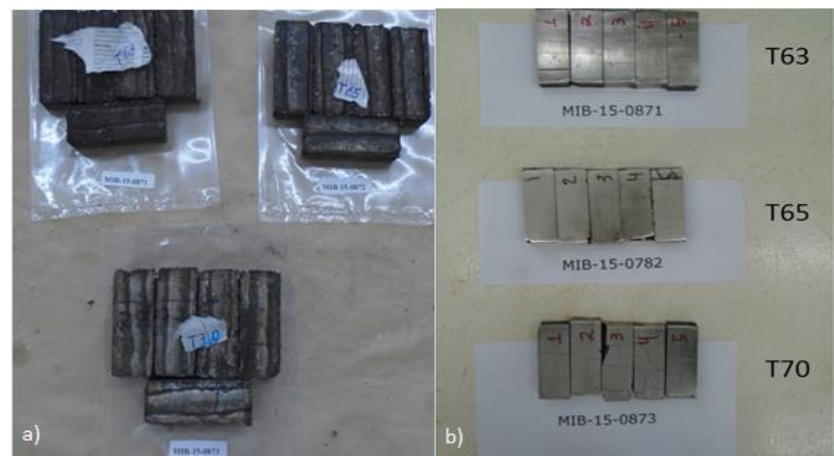

Figura 2. Amostras: a) antes do processo de retífica; b) após processo de retífica.

\subsection{Caracterização metalúrgica das amostras}

A análise da composição química do metal de base e dos revestimentos das ligas foram realizadas através de um espectrômetro de emissão óptica por centelhamento. Para realização da análise microestrutural das amostras, foram adotados os seguintes procedimentos:

- Corte de uma seção transversal à superfície nas dimensões 25 x 25 mm;

- Embutimento à quente em baquelite;

- Lixamento utilizando granolumetrias de 80, 120, 240, 360, 600, 1200, 1500 e 2000;

- Polimento com giz de óxido de cromo de 1,0 $\mu \mathrm{m}$;

- $\quad$ ataque ao metal de base utilizou-se Nital $2 \%$ durante dois segundos e do revestimento, Villela entre cinco a dez segundos;

- As microestruturas foram analisadas por microscopia óptica;

\subsection{Análise dos mecanismos de desgaste}

A análise das trilhas de desgaste foi realizada utilizando microscópio confocal 3D, modelo DCM3D. Foram realizadas as micrografias superficiais e imagens tridimensionais dos relevos das três ligas para apenas uma camada de deposição de solda.

\subsection{Ensaios de dureza e microdureza}

Os ensaios de dureza das amostras foram realizados em durômetro modelo 4JR, Rockwell C, com carga de $150 \mathrm{kgf}$ com penetrador tipo cônico de diamante conforme norma ASTM E18-15. Através das amostras embutidas, foram traçados os perfis de microdureza Vickers das ligas desde a superfície do revestimento duro em duas camadas até a região de transição com o metal de base.

\subsection{Ensaios de desgaste abrasivo roda de borracha}

Para a realização dos ensaios de desgaste abrasivo tanto para o metal de base como para os revestimentos foi utilizado o abrasômetro roda de borracha conforme norma ASTM G65-04. Os ensaios foram realizados para uma e duas camadas de 
deposição em todas as três ligas de revestimento especificadas, além do metal de base A-36 como referência. As amostras foram pesadas em uma balança analítica antes e depois dos ensaios de desgaste abrasivo realizados. Desta forma, foi possível obter a perda de massa e volume. Para cálculo do volume médio de desgaste do metal de base foi considerada uma densidade de $7,86 \mathrm{~g} / \mathrm{cm}^{3}$ (aço não ligado) e para os cálculos dos volumes de desgaste dos revestimentos das ligas foi considerada uma densidade de $7,80 \mathrm{~g} / \mathrm{cm}^{3}$ (aço ligado ao cromo).

\section{RESULTADOS E DISCUSSÃO}

\subsection{Caracterização da microestrutura do metal de base}

A Figura 3 apresenta a microestrutura do material de base utilizado para a deposição das ligas de revestimento T63, T65 e T70. O metal apresenta uma microestrutura de ferrita e perlita fina caracterizando-o como um aço baixo carbono conforme SAE 1020 ou A-36 conforme ASTM.

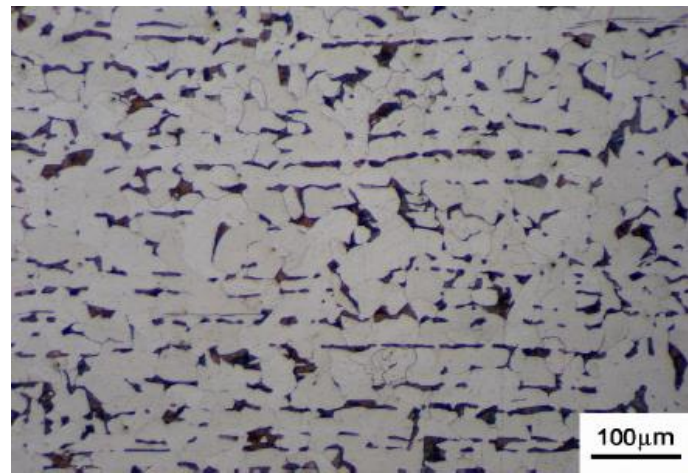

Figura 3. Micrografia do aço A-36 em seu estado como recebido para a deposição das ligas.

\subsection{Dureza do metal de base}

$\mathrm{Na}$ Tabela 4, encontram-se as medições de dureza realizadas no metal de base.

Tabela 4. Medições de dureza HRB para o metal de base.

\begin{tabular}{cccccccc}
\hline Metal & \multicolumn{7}{c}{ Dureza (HRB) } \\
\hline & Ensaio 1 & Ensaio 2 & Ensaio 3 & Ensaio 4 & Ensaio 5 & Ensaio 6 & Média \\
\hline A36 & 76 & 77 & 76 & 78 & 76 & 76 & 77 \\
\hline
\end{tabular}

\subsection{Ensaio de desgaste abrasivo roda de borracha no metal de base}

A perda de massa média do A-36 foi de 193,4 mg e considerando a densidade média do aço não ligado em $7,86 \mathrm{~g} / \mathrm{cm}^{3}$, a perda de volume média calculada conforme equação 3 foi de $24,61 \mathrm{~mm}^{3}$. Não foi necessária realizar a correção de diâmetro da roda de borracha, pois foi desprezível.

\subsection{Caracterização da microestrutura dos revestimentos}

$\mathrm{Na}$ análise micrográfica da liga T63, constata-se uma microestrutura típica de ferro fundido branco com carbonetos de cromo em matriz martensítica. Através da Figura 
4 (parte superior) percebe-se na superfície que os tamanhos dos carbonetos de cromo não são uniformes (destacado no círculo), há carbonetos de diversos tamanhos (uns mais finos e outros mais espessos), o que altera a microestrutura em termos de frações volumétricas de carbonetos em diferentes regiões.

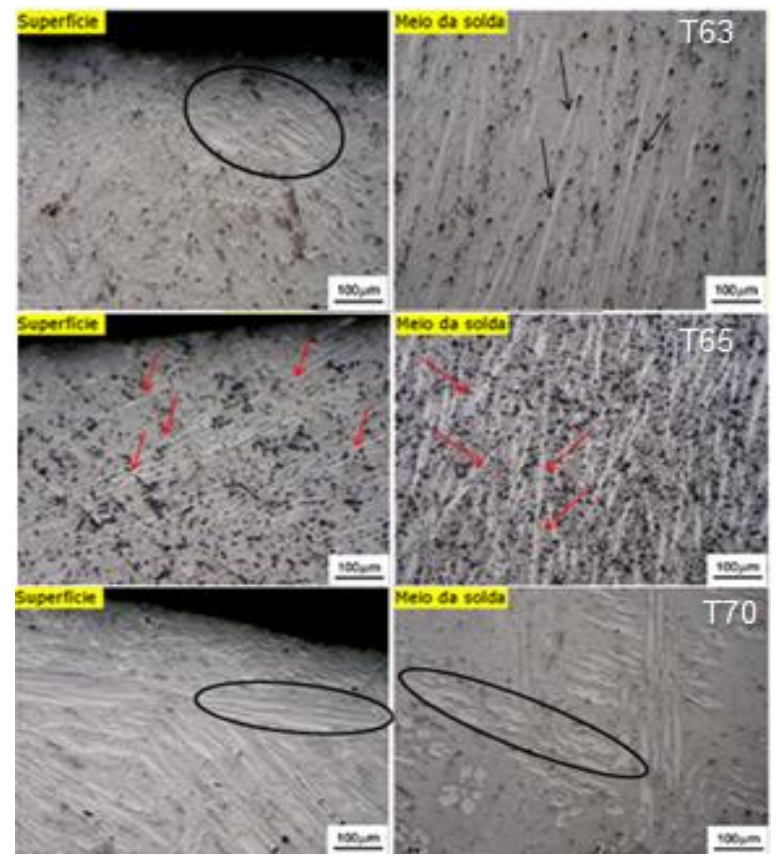

Figura 4. Micrografias das ligas de revestimento: superior - T63; intermediária; - T65; inferior - T70.

A micrografia da amostra T65 apresenta uma microestrutura com carbonetos de cromo e nióbio em matriz martensítica. Observa-se que, com a presença de carbonetos de nióbio, tem-se uma microestrutura mais refinada e homogênea (destacados pelas setas em vermelho) em relação aos carbonetos de cromo da liga T63. Estes carbonetos em tamanhos menores podem influenciar de maneira significativa na resistência ao desgaste abrasivo, pois a fração volumétrica e distribuição dos carbonetos são dos mais importantes parâmetros microestruturais na resistência ao desgaste. Hutchigns (1992) [5] afirma que para uma determinada fração volumétrica de carbonetos, a resistência ao desgaste abrasivo é aumentada para carbonetos finamente distribuídos com um pequeno espaço entre partículas.

Outro fator importante a destacar é que provavelmente houve a formação de carbonetos complexos contendo cromo e nióbio juntos.

A liga T70 apresentou uma microestrutura muito similar à liga T63 devido possuírem composição química similar. A principal diferença que pode ser constatada em função dessa maior quantidade de cromo é em relação aos tamanhos dos carbonetos. Importante destacar que para carbonetos maiores distribuídos na matriz, estes poderão levar à deformação plástica ou à fratura, dependendo da carga por partícula, da geometria, do tamanho e das propriedades mecânicas em geral, (HUTCHINGS, 1992). Se o tamanho dos carbonetos, por exemplo, for menor que a escala de danos, o material se comportará como um sólido homogêneo. Se as partículas de carbonetos são iguais ou maiores aos danos causados, o material responderá heterogeneamente.

\subsection{Fração volumétrica de carbonetos nas ligas}


Para a análise de fração volumétrica de carbonetos das ligas, cinco medições foram realizadas de forma aleatória em uma seção transversal da amostra. Verifica-se que a liga T70 apresenta a maior fração volumétrica de carbonetos distribuídos em sua matriz, seguida da liga T65 e posteriormente a T63. Uma das razões deste resultado provavelmente está no fato da T70 conter um teor maior de carbono e de cromo em relação às demais.

Tabela 5. Fração volumétrica de carbonetos das ligas.

\begin{tabular}{cccccc}
\hline \multicolumn{7}{c}{ Fração volumétrica de carbonetos } \\
\hline Liga & $\%$ & Liga & $\%$ & Liga & $\%$ \\
\hline T63 - 01 & 58,90 & T65 - 01 & 59,12 & T70 - 01 & 70,50 \\
T63 - 02 & 65,08 & T65 - 02 & 65,91 & T70 - 02 & 65,64 \\
T63 - 03 & 56,90 & T65 - 03 & 57,61 & T70 - 03 & 62,71 \\
T63 - 04 & 62,20 & T65 - 04 & 62,97 & T70 - 04 & 72,30 \\
T63 - 05 & 55,40 & T65 - 05 & 63,60 & T70 - 05 & 68,53 \\
Média & 59,70 & Média & 61,86 & Média & 67,93 \\
Desvio Padrão & 3,94 & Desvio Padrão & 3,42 & Desvio Padrão & 3,83 \\
\hline
\end{tabular}

A liga T65 apresentou uma fração volumétrica de carbonetos acima dos $60 \%$, um pouco a mais que a T63. Uma observação importante para a liga é que mesmo apresentando uma fração volumétrica menor que a T70, seus carbonetos se distribuíram de uma forma uniforme na matriz conforme visualizada na caracterização.

Em compensação, a liga T63 além de apresentar uma fração volumétrica de carbonetos inferior às outras, destaca-se também pela dispersão na distribuição dos mesmos em sua microestrutura, resultado este que pode influenciar de forma negativa na taxa de desgaste do seu revestimento, pois além de obter menos carbonetos, estes se concentram em determinadas regiões e deixam a matriz exposta em outras.

\subsection{Dureza Rockwell C (HRC)}

As medições de dureza dos revestimentos foram realizadas nas superfícies das amostras em duas etapas. Primeiramente houve a medição para os revestimentos contendo duas camadas de deposição e posteriormente para apenas uma camada. $\mathrm{Na}$ Figura 5, estes valores podem ser analisados.

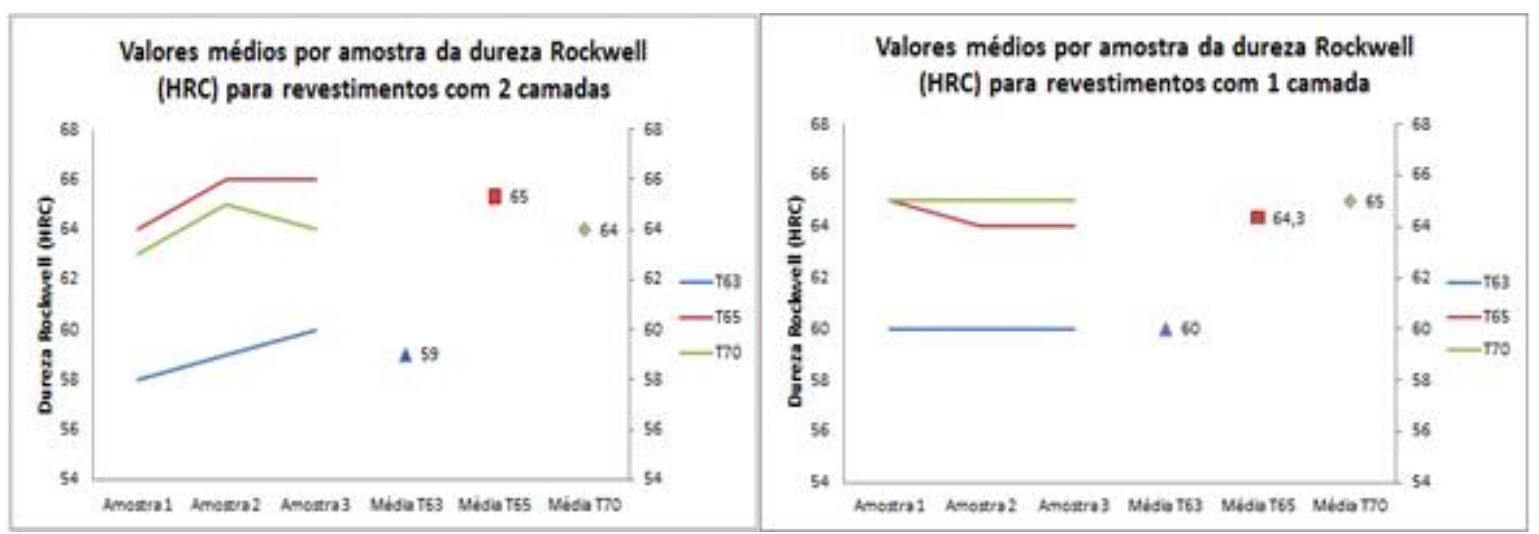

Figura 5. Dureza das ligas de contendo duas e uma camada de deposição, respectivamente.

A dureza é um bom parâmetro de avaliação a resistência ao desgaste abrasivo, mas vale ressaltar que nem sempre o material mais duro é o mais resistente ao desgaste. 
Este valor de dureza maior na liga T65 deve-se muito provavelmente pela presença dos carbonetos de nióbio formados em sua microestrutura.

\subsubsection{Microdureza Vickers (HV)}

Como forma de identificar as durezas desde a superfície do revestimento até o metal de base A-36, foram traçados os perfis de microdureza Vickers (HV) das amostras que se encontravam embutidas em baquelite para análise micrográfica. Tanto a liga T65 quanto a liga T70 obtiveram os valores mais altos. Pode-se dizer que a primeira foi afetada pelo teor de nióbio adicionado, pois estes carbonetos podem chegar a valores acima de $2400 \mathrm{HV}$, muito mais duros que os de cromo. Já a segunda, podese dizer que sua dureza aumentou em função da quantidade maior de cromo como também o seu tamanho.
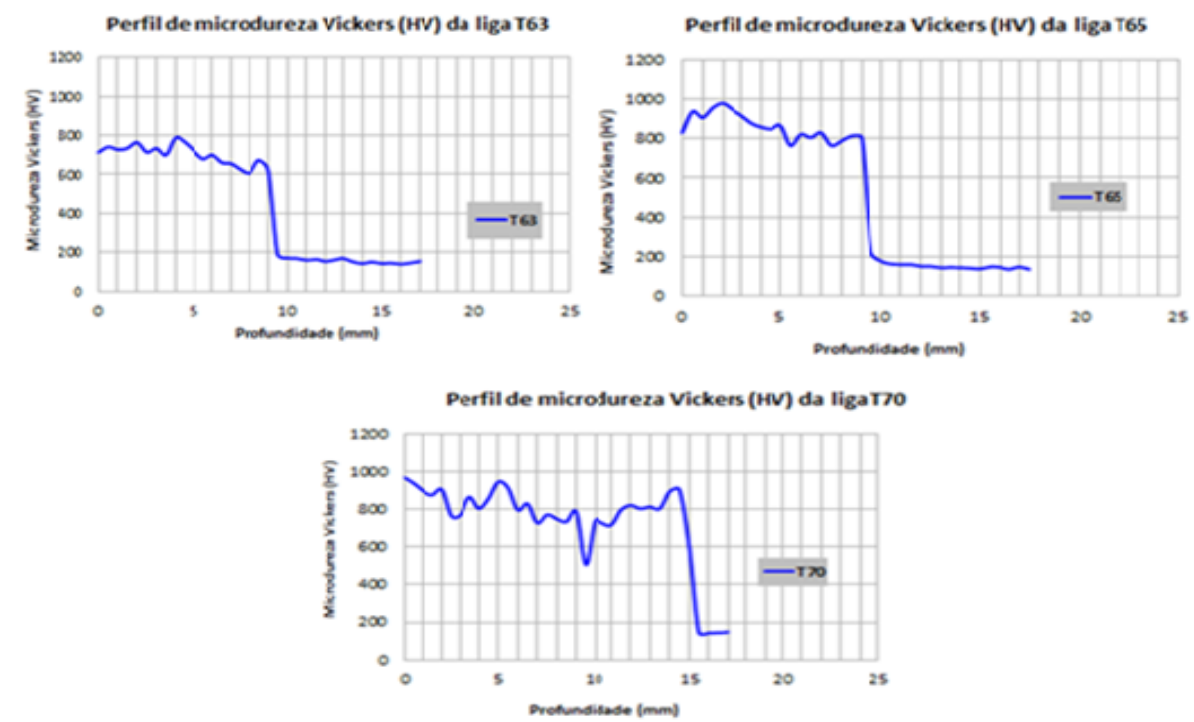

Figura 6. Perfis de microdureza Vickers das ligas de revestimento T63, T65 e T70.

\subsubsection{Ensaios de desgaste abrasivo}

Os resultados da perda de volume média tanto para uma camada quanto para duas camadas podem ser notados na Figura 7.

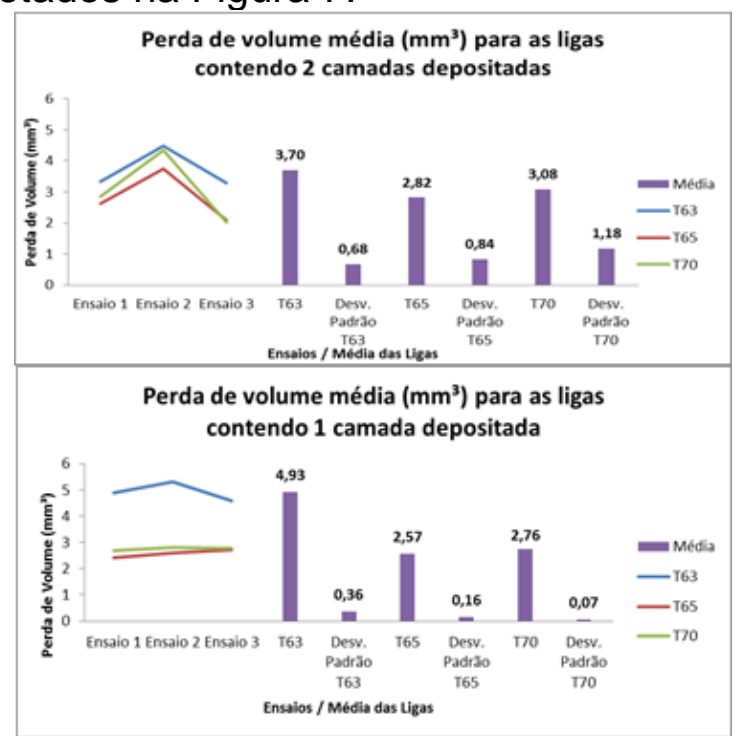

Figura 7. Análise comparativa da perda de volume média entre as ligas de revestimento. 
Analisando os resultados para duas camadas de soldagem, a liga T65 obteve o melhor resultado em valores absolutos comparando-se às demais ligas ensaiadas nas mesmas condições e procedimentos adotados. Analisando-se os resultados apenas para uma camada de solda depositada, verifica-se uma menor variação das perdas de massas entre as amostras de uma mesma liga. Novamente a liga T65 apresentou o melhor desempenho de desgaste abrasivo, seguida da liga T70. A liga T63 foi a única que aumentou drasticamente seu desgaste com apenas uma camada de deposição, sendo que as ligas T65 e T70 se comportaram de forma quase que proporcional em relação às suas perdas médias em volume para duas camadas, ainda que obtiveram desempenho superiores.

\subsubsection{Análise das trilhas e dos mecanismos de desgaste}

Na Figura 8, é possível observar como as superfícies das amostras ficaram após os ensaios de desgaste abrasivo roda de borracha. Pode-se constatar que todas as superfícies são caracterizadas por trincas devido às características dos revestimentos, com elevada dureza e alta temperatura de soldagem. Estas trincas podem levar a um mecanismo de desgaste por fratura como definido por Zum Gahr (1987), quando ocorre o microcracking ou lascamento em carregamentos impostos pela partícula abrasiva em superfícies de materiais quebradiços.

As trilhas de desgaste abrasivo podem ser visualizadas mais nitidamente nos corpos de prova das ligas T63 e T70, Figura 8a e Figura 8c, respectivamente. Na liga T63, constatam-se vários riscos profundos e aparentemente uma área de desgaste maior que nas outras amostras. A liga que possui um maior percentual em massa de cromo, T70, também é caracterizada pela presença de riscos, mas visualmente apresentando uma profundidade de desgaste superior à liga T63 e uma trilha de desgaste mais concentrada.

No corpo de prova do meio, liga T65 contendo nióbio, visualmente observa-se maior uniformidade do desgaste do revestimento apresentando uma superfície com riscos mais finos e de menor profundidade, além de uma área de desgaste também menor que as demais ligas.

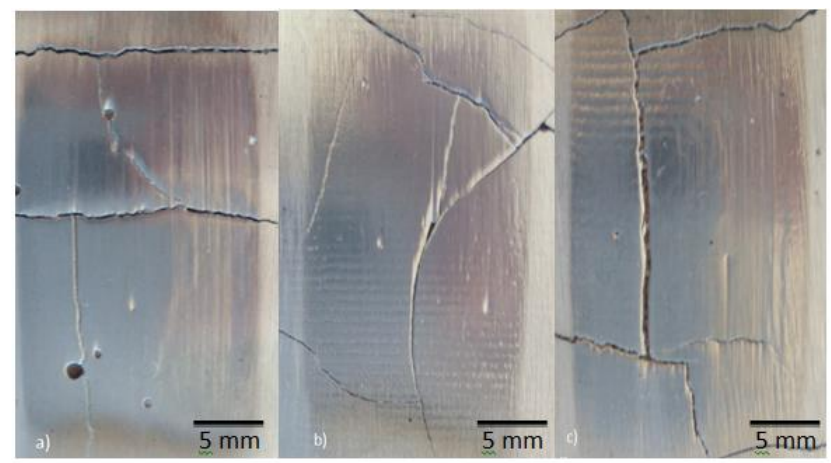

Figura 8. Trilhas de desgaste dos corpos de prova após os ensaios de abrasão por roda de borracha; a) liga T63; b) liga T65; c) liga T70.

Na Figura 9, observam-se os relevos encontrados nas três ligas após o corte da primeira camada de soldagem. Estas fotografias foram registradas no microscópio confocal 3D sob um aumento de 50 vezes. As partes mais voltadas para o tom de azul representam profundidades de desgaste mais acentuadas ao contrário das mais claras na qual há proximidade com a superfície do revestimento. 


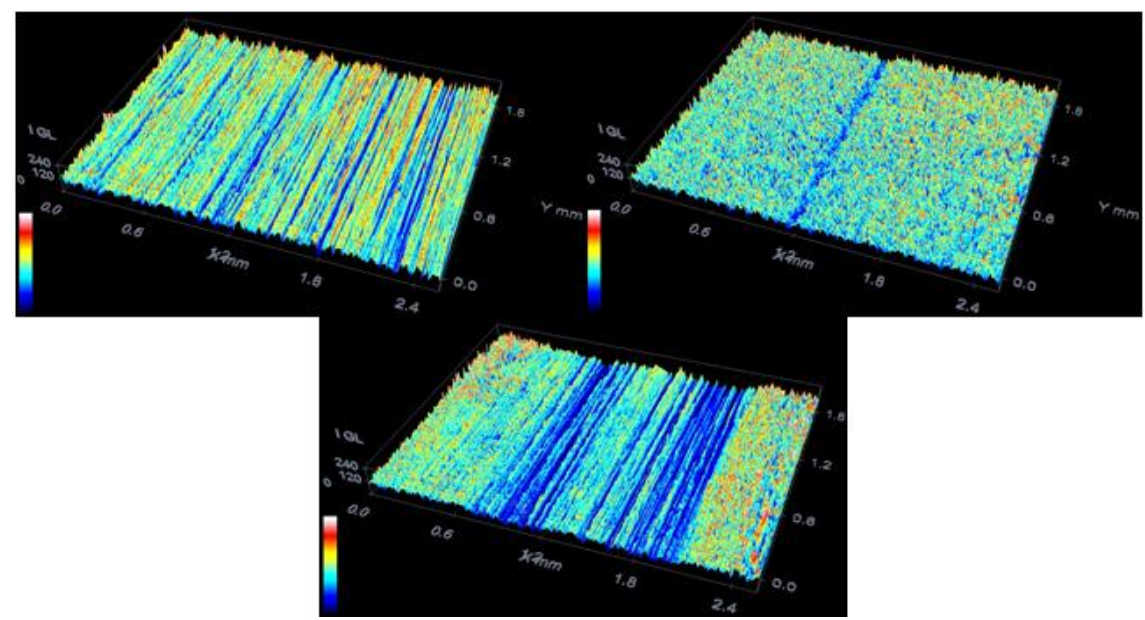

Figura 9. Fotografias dos relevos em um aumento de 50X retiradas no microscópio confocal 3D. Esquerda: liga T63; Direita: liga T65; Abaixo: liga T70.

Fica evidente que a liga T63 obteve diversos vales (microcortes) acentuados de desgaste, o que pode ter levado a um pior desempenho em relação às demais ligas. Já a liga contendo nióbio constata-se um relevo muito mais homogêneo resultando em uma maior resistência ao desgaste abrasivo, provavelmente devido uma quantidade maior de elementos formadores de carbonetos e estes estarem distribuídos mais uniformemente na matriz.

Ainda na liga contendo nióbio, verifica-se que há um risco central com profundidade mais elevada. Em uma análise mais macro (visual) desta amostra, observou-se que a região a qual sofreu o desgaste abrasivo no ensaio roda de borracha se localizou muito próxima a uma trinca existente, o que pode ter influenciado nesta caracterização do mecanismo de desgaste sofrido nesta região central da figura.

O relevo da liga T70 visualizado na parte inferior da figura comprova a concentração do desgaste em uma determinada região conforme discutido anteriormente. Este fato muito provavelmente se caracteriza pela alta concentração de carbonetos de cromo em tamanhos maiores distribuídos na matriz, o que pode levar a um arrancamento de material devido a relação tamanho do dano causado pela partícula abrasiva e o tamanho do carboneto, como descrito por Hucthings (1992).

\section{CONCLUSÕES}

No estudo da resistência ao desgaste de chapas usadas em transferência de minério ou como moegas alimentadoras de pelotas de minério de ferro, podem ser feitas as seguintes conclusões:

- A aplicação de revestimentos $\mathrm{Fe}-\mathrm{Cr}-\mathrm{C}$ contendo $\mathrm{Nb}$ oferece a maior resistência ao desgaste abrasivo. As chapas quando revestidas com duas camadas ou mesmo com uma única camada apresentaram as menores perdas de volume médio $\left(\mathrm{mm}^{3}\right)$ de desgaste.

- Os revestimentos $\mathrm{Fe}-\mathrm{Cr}-\mathrm{C}$ contendo $\mathrm{Nb}$, mesmo com baixos teores de $\mathrm{Cr}$, possuem dureza similar aos revestimentos $\mathrm{Fe}-\mathrm{Cr}-\mathrm{C}$ não modificados, em razão da alta dureza do carboneto de nióbio, que praticamente dobra a dureza na superfície. Tais revestimentos chegam a alcançar uma dureza de 65 HRC.

- A adição de $\mathrm{Nb}$ permitiu a formação de carbonetos de nióbio e cromo finamente distribuídos na matriz, resultando em uma microestrutura bem mais homogênea. 
Aliada à alta dureza alcançada, esse fator contribuiu para a obtenção de revestimentos com os melhores resultados de desgaste nos testes abrasivos.

- Em termos de perda de volume de desgaste, as chapas revestidas com uma única camada de liga contendo $\mathrm{Nb}$ apresentaram valores de 8,0 a 9,0 vezes maiores frente às chapas metal base aço carbono A-36. As chapas revestidas contendo $\mathrm{Nb}$ obtiveram resultados da ordem de 30,0\% superior na resistência ao desgaste abrasivo em relação às chapas utilizadas atualmente e $8,0 \%$ frente à liga que contém alto $\mathrm{Cr}$.

- Para as ligas $\mathrm{Fe}-\mathrm{Cr}-\mathrm{C}$ contendo $\mathrm{Nb}$, a fração volumétrica de carbonetos foi da ordem de $60 \%$ e se distribuíram de maneira uniforme na matriz. Notou-se também que seus carbonetos ocasionaram um refinamento da microestrutura, o que provavelmente influenciou na maior resistência ao desgaste abrasivo.

- Os mecanismos de desgaste predominantes nos revestimentos Fe-Cr-C foram o microcorte e o microssulcamento, verificando-se que o aumento do teor de $\mathrm{Cr}$ promove uma diminuição na quantidade de riscos ocasionando um desgaste mais concentrado. Nos revestimentos $\mathrm{Fe}-\mathrm{Cr}-\mathrm{C}$ contendo $\mathrm{Nb}$ prevalece $\mathrm{O}$ mecanismo por rolamento, uma vez que as trilhas de desgaste não se apresentaram com direção preferencial de desgaste.

- Através do trabalho realizado, constatou-se que a microscopia confocal 3D é uma ótima ferramenta de análise dos mecanismos de desgaste em uma superfície. Além da detecção do mecanismo, esta ferramenta também auxilia na análise do relevo após o desgaste.

- Através da análise de viabilidade econômica, o retorno custo $\mathrm{x}$ benefício para a liga $\mathrm{Fe}-\mathrm{Cr}-\mathrm{C}$ contendo $\mathrm{Nb}$ é superior às demais ligas. Apesar de o custo aproximado desta liga ser $25 \%$ superior em relação a de baixo $\mathrm{Cr}$, é esperada uma vida útil superior a $30 \%$ em relação ao desgaste. Levando-se ainda em consideração os custos indiretos com manutenção, este retorno aumenta consideravelmente.

- Deste trabalho extrai-se uma importante recomendação tecnológica: dado aos melhores desempenhos nos ensaios roda de borracha dos revestimentos $\mathrm{Fe}-\mathrm{Cr}$ $\mathrm{C}$ contendo adições de $\mathrm{Nb}$ e análise de viabilidade econômica positiva, deve-se aplicar em campo as chapas contendo revestimentos com $\mathrm{Nb}$ em substituição aos revestimentos Fe-Cr-C.

\section{REFERÊNCIAS}

1 DIAS, M. F.; GOMES, S. I. Avaliação da Resistência ao Desgaste abrasivo a Baixa Tensão de Revestimentos soldados por arco submerso. II Congresso Brasileiro de Engenharia de Fabricação, São Paulo, 2003.

2 BHUSHAN, B.; GUPTA, B.K. Handbook of Tribology: Materials, coatings and surface treatments. p.1168. 1991.

3 ZUM GAHR, K. H. Microstructure and wear of materials. Tribology Series. v.10. Elsevier Science Publishers. 560p. Amsterdam. 1987.

4 BRANDI, S.D.; WAINER, E.; DE MELLO, F.D.H. Soldagem: processos e metalurgia. Editora Blucher. p.494. São Paulo, 2013.

5 HUTCHINGS, I.M. Trybology: Friction and wear of engineering materials. CRC Press Inc., Boca Raton, USA, 273p. 1992. 